\section{Desynchronisation der zirkadianen Rhythmen}

Helga Peter ${ }^{1}$ und Thomas Penzel ${ }^{2}$

${ }^{1}$ Marburg, Deutschland

${ }^{2}$ Interdisziplinäres Schlafmedizinisches Zentrum, Charité Universitätsmedizin Berlin, Berlin, Deutschland

\section{Englischer Begriff}

desynchronisation of circadian rhythms

\section{Definition}

Die Schlafphase liegt regelhaft nicht synchron mit dem physikalischen Tag-Nachtrhythmus.

Siehe auch

- „Chronobiologie“

- $>$,Jetlag“

- „Zirkadiane Schlaf-Wach-Rhythmusstörungen“ 